\title{
The idea of non-restricted use of LV networks by electricity consumers, producers, and prosumers
}

\author{
Mateusz Szablicki ${ }^{1,2^{*}}$, Piotr Rzepka ${ }^{1,2}$, Maciej Sołtysik ${ }^{2}$, and Rafat Czapaj ${ }^{2}$ \\ ${ }^{1}$ Silesian University of Technology, Institute of Power Systems and Control, Gliwice, Poland \\ ${ }^{2}$ PSE Innovations Ltd., Warsaw, Poland
}

\begin{abstract}
Until now, electricity users are being connected to the LV networks by a physical electricity consumption point. In this point an electricity meter is assigned to each and every one user. A given user may use the flowing electricity only by the meter assigned to him at the consumer-specific point. This is a significant limitation in the nonrestricted access to the power network. The Authors come with an idea to eliminate this restriction. The paper presents the concept of virtualization of a physical point of electric power consumption in a LV network. The proposed novel idea of using the power network will ensure the expected non-restricted access to any point of the power network for users. This seems particularly important nowadays and is dictated by the growing expectations of users' mobility. The presented concept is dedicated especially to networks in the form of clusters (cooperatives) or energy clouds. Its application in LV networks will significantly simplify the users' use of the power infrastructure, also in the aspect of financial settlements. This should also contribute to the rapid significant development of electromobility.
\end{abstract}

\section{Background issues}

A power system (PS) is a platform for electricity exchange among its users. One of the users is the electricity final user/consumer (FC). It is a Producer of electricity (generating entity) or an Electricity Consumer connected to a Low Voltage (LV) network in PS. The Producer inputs electricity to the PS, while the Consumer takes this electricity from the PS. A combination of a Consumer and a Producer is a Prosumer.

Usually a single FC has little knowledge about the functioning of the PS. That is why many FCs treat PS as a virtual electricity (power) storage. In their understanding, such a storage will take all the electricity from the Producers and will make it possible for the Consumers to consume any amount of electricity they might need. Moreover, many FCs want to have the freedom of time and location to dispose of electricity within this power storage. However, currently it is impossible. One of the reasons is the current manner of connecting FCs to a LV network in a PS.

* Corresponding author: mateusz.szablicki@polsl.pl 
A single FC is connected to the LV network by the Point of Physical Collection (PPC). The rule applies - each FC has its own PPC. Thus, a FC can only consume electricity from its own PPC without any problems. This is a significant limitation in access to the PS, in particular in view of the growing expectations towards a FC mobility. This can be minimized by FPP virtualization.

The authors' idea will undoubtedly facilitate the use of FC with PS. This will create conditions for the rapid development of electromobility. It will also allow further dissemination of prosumer micro-installations.

\section{The existing LV network model with the PPC}

In the LV network the FCs are connected to the PS via the individual PPCs. The PPC is the point of connection of the PS with an internal network of the FC, with its loads and sources. Each PPC is equipped with an Individual Electricity Meter (IEM) which is assigned to one FC and one PPC. An illustration of the existing LV network model with a PPC is shown in Figure 1.

\section{Consumer A}

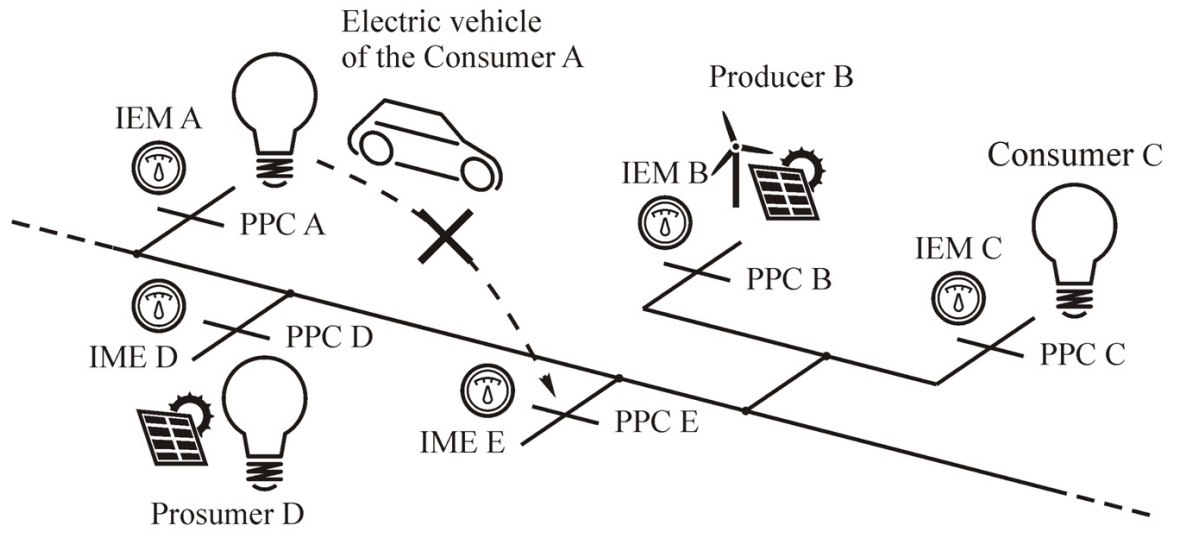

Fig. 1. The existing model of the LV network with the PPC (based on [1]).

The advantage of the LV network model with the PPC is the ease of electricity billing. Every IEM allows the measurement of electricity consumed from the PS or introduced to the PS by the FC for its own PPC. This measurement made by consumer's IEM is the only amount needed for settlements between FC and the electricity seller. Every PPC also facilitates the identification of every FC. Each FC is perceived by the electricity seller only through the prism of the IEM in the PPC.

However, in the existing LV network model with the PPC each and every FC use the PS only through their own PPC. The FCs are not able to freely join other LV network points. For example, the FC presented in Figure 1 of in the form of Consumer A (connected to the PPC A) cannot easily connect to another PPC (in a illustrative manner, to PPC E). The point PPC E is not assigned to this FC. This prevents the settlement of electricity consumed in PPC E in a single invoice. Such a bad situation may apply to the Consumer A with an electric vehicle. The Consumer A can only charge his vehicle in PPC A and be billed as part of this point. Charging the vehicle in another PPC requires access to dedicated services usually provided by entities other than the seller who serves it. This forces separate payments. This is a hindrance. Such a situation is illustrated in Figure 2. 


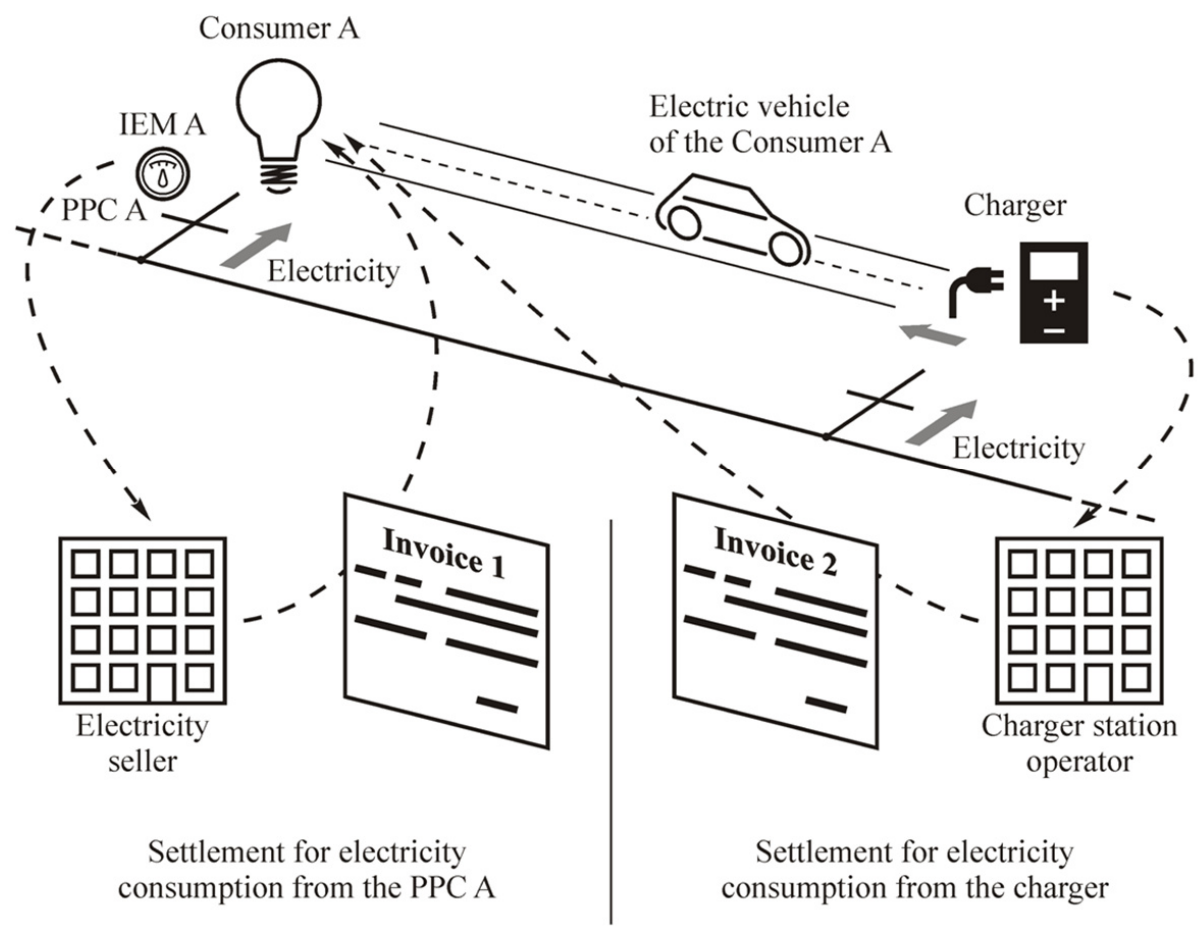

Fig. 2. The existing complicated FC settlement model in the LV network with the PPC (based on [1]).

Another problem was also identified for the FC in the LV network with the PPC. This problem may increase in the future. This problem is a difficulty in connecting of a Mobile Electric Energy Storage (MEES). The MEES is, among others, an electric vehicle, mobile (transportable) batteries, etc. The existing LV network model with the PPC makes it difficult to use MEES as a source of electricity. Currently, this is possible only in the FC internal network, after connecting behind consumer's own PPC. There are two ways of using MEES. In the first a MEES is able to generate electricity to the PS - but it requires a two-way IEM installation. This is necessary for the settlement of the MEES generation. In the second approach, a MEES is a source of electricity dedicated for FC's own needs. However, then the electricity from a MEES cannot be introduced into the PS. Difficulties in the use of MEES are illustrated in Figure 3.

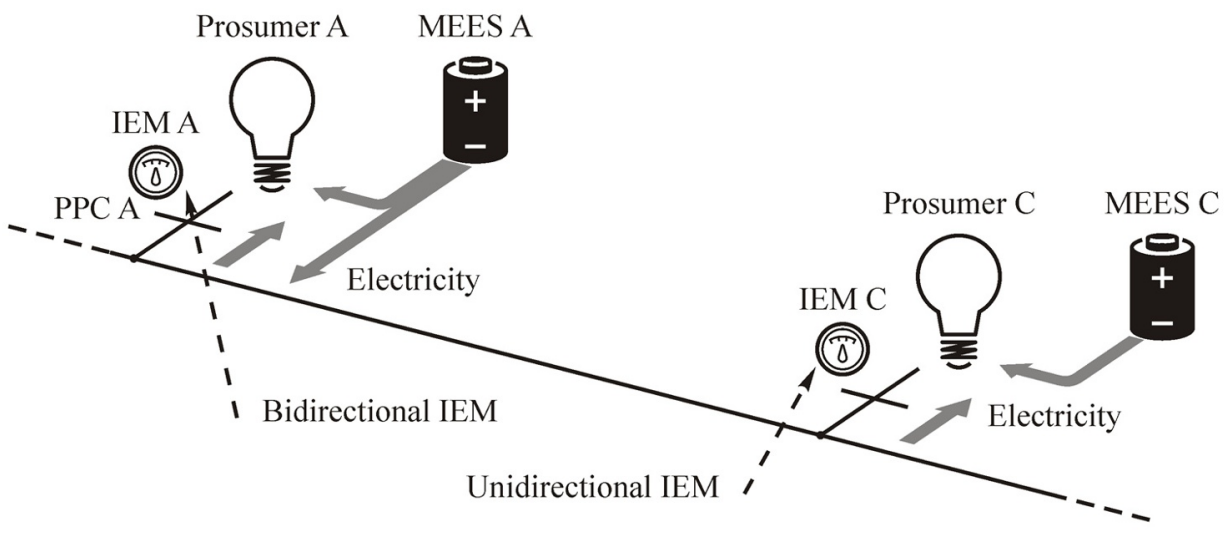

Fig. 3. Existing difficulties in connecting the MEES in the LV network with the PPC. 
The freedom and convenience of using the FC with the PS can be significantly increased. The previous restriction imposed by FC belonging to only one PPC can be eliminated. It is proposed to virtualize the PPC by introducing Virtual Points of Connection (VPC).

\section{A New LV network model with a VPC}

The most important change in the new LV network model is to stop assigning the electricity meter to a single FC. In the LV network model with a VPC, the meter is assigned only to the connection point. The meter can be made available to any $\mathrm{FC}$ willing (differently than before). Providing a meter for the FC is synonymous with the ability to consume/generate electricity to the PS via a logged-in FC. Thus, the VPC is the point of connection in the LV network, which can be used by any FC. This requires the installation of meters in the VPC that will allow the identification of the FC currently using the given VPC (Common Electricity Meter - CEM).

The transition from the PPC to the VPC will facilitate and increase the FC mobility in the LV network. The FCs can easily join any VPC (taking into account the obvious technical limitations e.g. the nominal voltage level). The freedom of connection also applies to the FC elements that can be connected to the different VPCs. The comparison of the LV network functionality with the PPC and the VPC is presented in Figure 4.

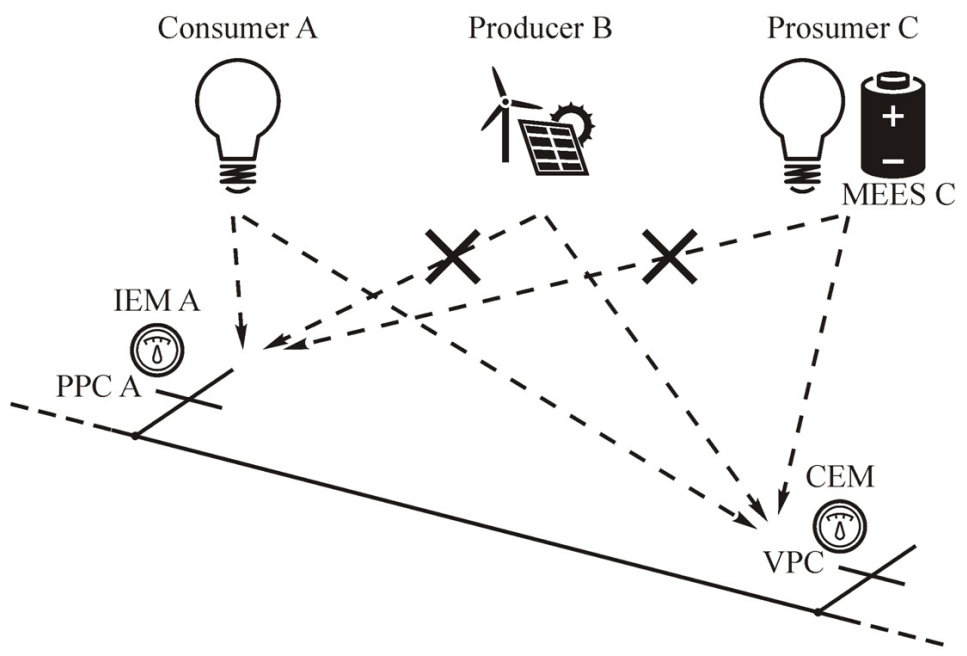

Fig. 4. Difference in the LV network with the PPC and the VPC.

In the proposed new LV network model from VPC to FC relation - the electricity seller introduces an additional element of the chain of contacts. This is a Measurement Operator (MO). The MO plays the role of the CEM supervisor. The basic MO tasks are:

- management of CEMs installed in VPC;

- verification of FC's rights, which wants to use the VPC;

- allowing the identified FC to use the VPC;

- acquisition of information about the FC currently using the individual VPCs;

- acquisition of information on the time of use of a given VPC by each FC;

- acquisition of information on the level of electricity consumed/generated in a given VPC by each FC;

- distribution of collected information to FC settlement entities (electricity seller) and entities supervising the PS elements (power grid operator, charger station operator, etc.). 
Eventually, the MO can be a component of the Measurement Operator of Information (MOI) of the entire PS. In Poland, works on a project of such an operator are underway. They are at the stage of arrangements $[2,3]$.

The role of the electricity seller is limited to aggregation of information on the activities of any given FC, limited to contracts with the FCs. This information will come from MO and other entities (for example: the charger's station operator).

The basic set of information retrieved by the electricity seller from the MO includes:

- the set of the used VPCs;

- time of using the individual VPCs;

- the level of electricity consumption in individual VPCs;

- the level of electricity generation in individual VPCs.

On the other hand, the seller downloads a similar set of information on the use of elements subordinated to this entity (for example: charger for electric vehicles - a station operator of the charger).

The information collected is the basis for calculating the consumption/generation of electricity by the FC and financial settlements between the electricity seller and the FC. In such a FC - MO relationship concept - the electricity seller will simplify FC financial settlements. Even when using the multiple VPCs, the FC will receive one invoice from its electricity seller. Until now - for the LV network with the PPC - the FC is forced to regulate many payments on its own. The diagram of a simple $\mathrm{FC}-\mathrm{MO}-$ Seller relations is illustrated in Figure 5.

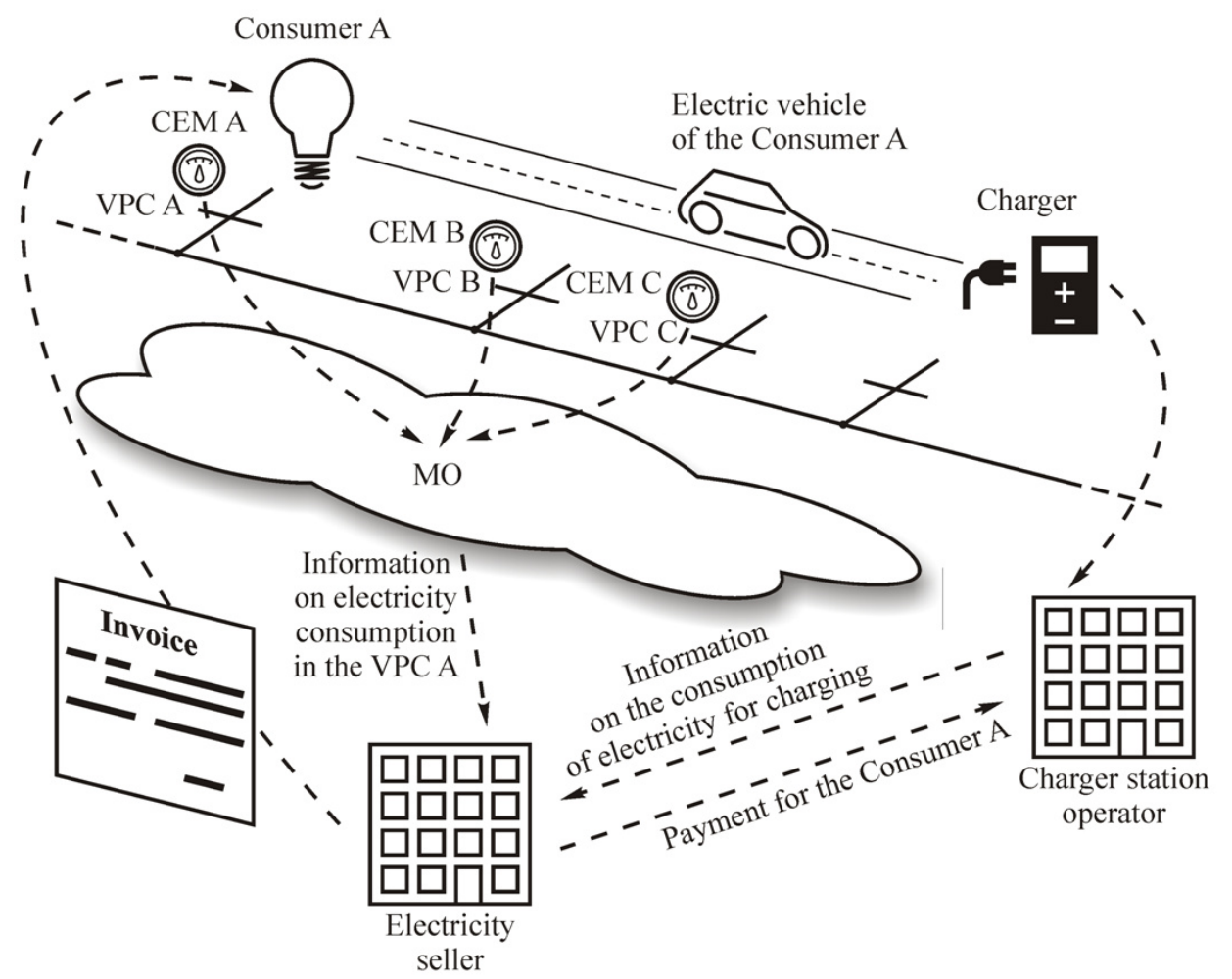

Fig. 5. A new simple FC settlement model in the LV network with VPC the (based on [1]).

For the new LV network model with the VPC, the FC access method will be changed. The VPC sharing scenario for the FC is shown in Table 1. 
Table 1. Stages of the FC connection to the VPC in the LV network.

\begin{tabular}{|c|c|c|c|c|}
\hline \multirow{2}{*}{ Stage } & Trustee & \multicolumn{2}{|c|}{ Executive element } & Action \\
\hline \multirow{2}{*}{1} & FC & & Mobile device & Manual FC request for access to the \\
VPC
\end{tabular}

\section{The VPC in the concept of the Energy Cloud}

The idea of a new model of the LV network with the VPC ideally fits into the assumptions of the Energy Cloud. In the concept of the Energy Cloud presented, among others in [4-7] the PS is treated as a virtual power storage, from which the FC can freely use and input or consume electricity at any time. Schematically, the idea of such an Energy Cloud dedicated to prosumers is presented in Figure 6.

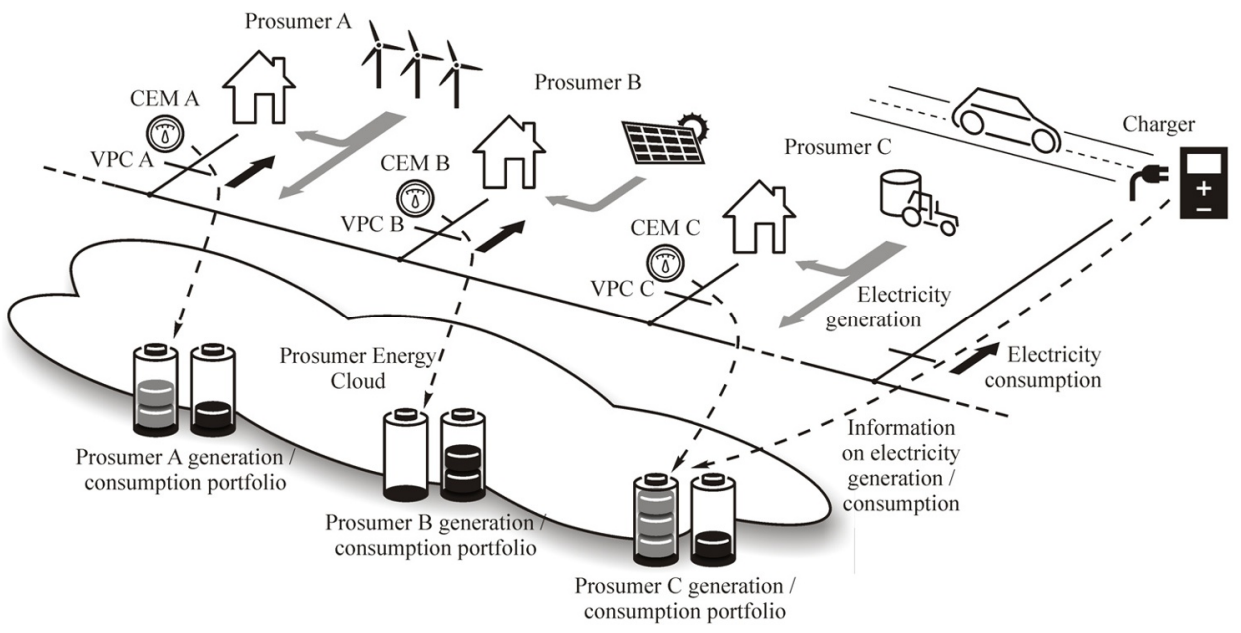

Fig. 6. The Idea of the Prosumer Energy Cloud (based on [1]).

The Energy Cloud should be characterized by freedom of the FC access to the PS. This creates a sharp requirement for how to connect the FC to the LV network. It must be possible to identify the FC. This is necessary to determine the level of electricity consumed/generated by a given FC. This requirement is easily implemented by the VPC, which is the idea of the authors in this paper. It removes one of the barriers to the spread of 
Energy Clouds. This is an important contribution of the authors to the development of the Energy Cloud concept.

\section{A Comparative assessment of the LV network with the VPC vs the PPC}

The detailed characteristics of the new LV network model with the VPC allows to indicate the unique features of the authors' idea. The disadvantages are also presented. This was compared to the features of the existing LV network with the PPC. The trustees of each feature are also indicated.

- the advantages of the existing LV network model from PPC:

- simple FC identification (applicable to the seller);

- easy FC financial settlement (applies to the seller);

- easy estimation of the expected level of payment/profit by the FC (applies to the FC);

- the disadvantages of the existing LV network model with the PPC:

- the FC's access to the PS is difficult except for its own PPC (applies to the FC);

- complicated (burdensome) approach to billing the FC using the non-own PPC many bills (applies to the FC);

- many entities accounting for the use the PS by the FC (applicable to the seller);

- the need to determine the nature of the PPC in advance as a consumption or generation point (applicable to the FC) or necessity to change the connection agreement;

- the advantages of the new LV network model with the VPC:

- easy FC access to the PS through the shared VPC (applicable to the FC);

- easy FC financial settlement (applies to the FC);

- one entity accounting for the use of the PS by the FC (applicable to the FC);

- simple and low-cost adaptation of the PS to the VPC concept (applicable to the $\mathrm{MO})$;

- free connection of power receivers and sources to the VPC (applicable to the FC);

- the disadvantages of the new LV network model with the VPC:

- the necessity of retrofitting the PS with electricity meters with the FC identification (applicable to the MO) - however, many existing electricity meters only need to be equipped with the FC identification module, which will make FC accessible to the given VPC;

- the establishment of the MO - however in many countries works on the creation of such an entity is already underway; the implementation of the VPC will undoubtedly accelerate this process.

The comparative assessment indicates that the introduction of the VPC instead of the PPC will help the FC to use the PS, thanks to the freedom to join any point of the LV network. This is particularly desirable for the observed growing expectation of the FC mobility. Undoubtedly, it will contribute to a significant and rapid development of electromobility. It is also expected to have a positive impact on further dissemination of dispersed energy sources in prosumer micro-installations. This leads the VPC application in the LV network.

\section{The VPC application}

The concept of virtualization of the physical point of consumption of the electricity user is particularly suited for the LV network in the form of clusters (cooperatives) or Energy 
Clouds [8-10]. The VPC will ensure the expected mobility and ease of use for the participants in these structures [11].

The authors' idea of the VPC introduction for the LV network may be the starting point for developing a completely new model of using the FC with the PS [12]. This also fits in with the idea of Smart Networks [13, 14].

To implement the subordinate MO structure it is possible to use Multi-Agent systems of area power system protection. This will significantly increase the reliability of data acquisition from the CEMs, which are the territorially dispersed MO measurement elements. An exemplary structure of an Multi-Agent of such a system is characterized in [15].

\section{References}

1. P. Rzepka, M. Sołtysik, M. Szablicki, Wirtualny punkt przyłączenia użytkownika energii elektrycznej w sieci niskiego napięcia, Rynek Energii, 132, 4 (2017)

2. Operator Informacji Pomiarowej w pytaniach i odpowiedziach [on-line]. https://smartgrids.pl (2017)

3. Koncepcja dotycząca modelu rynku opomiarowania w Polsce, ze szczególnym uwzględnieniem wymagań wobec Operatora Informacji Pomiarowej, URE (2012)

4. P. Rzepka, M. Sołtysik, M. Szablicki, Prosumencka chmura energii - koncepcja nowej usługi dla prosumentów, Zesz. N. In. Gosp. Sur. Min. i En. PAN, 98, 10 (2017)

5. The Impact of the Energy Could on the Power Sector [on-line]. https://www.nuenergen.com (2017)

6. E.ON zaproponuje prosumentom wirtualny magazyn energii SolarCloud [on-line]. https://gramwzielone.pl (2017)

7. D. Unger, J. Myrzik, Agent Based Managemet of Energy Storage Devices within a Virtual Energy Storage. 2013 IEEE Energytech, IEEE (2013)

8. Koncepcja funkcjonowania klastrów energii w Polsce, Ministerstwo Energii, 343 (2016)

9. J. Popczyk J., Klastrowy rynek energii elektrycznej. Wirtualna osłona klastrowa - net metering - selfdispatching (i restrukturyzacja elektroenergetyki), Bibl. źr. en. prosum., 11 (2016)

10. P. Rzepka, M. Sołtysik, M. Szablicki, Klaster energii - idea wdrażania w Krajowym Systemie Elektroenergetycznym, XX Sem. Autom. w El., 10 (2017)

11. Plan Rozwoju Elektromobilności w Polsce, Ministerstwo Energii, 36 (2016)

12. I. Chojnacki, Klastry energii mogą się okazać tylko preludium do wielkich zmian [online]. http://energetyka.wnp.pl (2017)

13. S. Leksawat, at all, Demonstration of cluster-based power system automation for future smart grids, 2016 IEEE Energycon, 6 (2016)

14. M. Sarwar, B. Asad, A review on future power systems; technologies and research for smart grids, 2016 ICET, 6 (2016)

15. A. Halinka, P. Rzepka, M. Szablicki, Agent Model of Multi-Agent System of Area Power System Protection, 2015 MEPS, 4 (2015) 